\title{
Effects of different types of exercise on muscle activity and balance control
}

\author{
Mi-Kyoung Kim, MS, PT ${ }^{1)}$, Jung-Hyun Choi, PT, PhD ${ }^{1)}$, Min-A Gim, MS, PT ${ }^{1)}$, \\ Young-Hwan Kim, $\mathrm{PhD}^{2)}$, Kyung-Tae Yoo, PT, $\mathrm{PhD}^{1) *}$ \\ 1) Department of Physical Therapy, Namseoul University: 21 Maeju-ri, Sungwan-eup, Seobuk-Gu, \\ Chonan-Si 331-707, Republic of Korea \\ 2) Graduate School Physical Education, Kyung Hee University, Republic of Korea
}

\begin{abstract}
Purpose] This study analyzed the effects of isotonic, isokinetic, and isometric exercises of ankle joint muscles on lower extremity muscle activity and balance control. [Subjects and Methods] The subjects were 30 healthy adults (15 males) in their 20s who were randomly assigned to three different exercise method groups of 10 people each. The isokinetic exercise group performed three sets at an angular velocity of $60 \%$ sec, including a single rest period after every set of 10 repetitions. The isometric exercise group performed three sets consisting of three 15 repetitions of a 15 -second exercise followed by a 5-second rest. [Results] Multivariate analysis of variance revealed that depending on the exercise method, the non-dominant tibialis anterior, gastrocnemius muscle, and peroneus longus showed significant differences in muscle activity for weight-bearing non-dominant sides; when the dominant side was weight-bearing, the dominant gastrocnemius and peroneus longus showed significant differences in muscle activity; and the non-dominant and dominant sides showed significant differences in balance control depending on the duration of support in the area. [Conclusion] Muscle fatigue from the three exercise methods produced a decline in muscle activity and balance control; due to the fatigue before exercise, the side that did not perform the exercises was affected.

Key words: Isotonic, Isokinetic, Isometric
\end{abstract}

(This article was submitted Jan. 26, 2015, and was accepted Mar. 7, 2015)

\section{INTRODUCTION}

Human posture is determined and maintained by muscle coordination, proprioception, equilibrioception, and the position and function of the joints ${ }^{1}$. The ankle strategy that is applied to the ankle joints is an important ${ }^{2}$ component of maintaining postural adjustment and includes the proper use of hip joint muscles attached to the ankle joints and appropriate stepping strategies ${ }^{3}$. In terms of mechanics, the ankle joint is important in gait and functional activity ${ }^{4}$. The maintenance of a sufficient range of motion, strength, and proprioception is crucial in providing shock absorption and balance control of movements in the lower extremities while walking, which are the primary functions of the ankle joints ${ }^{5)}$. Functional balance is the ability to maintain a position and adjust posture while moving from one postural position to a different position or a functional motion, such as movement from a certain position to another position ${ }^{6}$. The ankle joints are adjusted by the ground reaction force generated by the contractions of the gastrocnemius, pero-

*Corresponding author. Kyung-Tae Yoo (E-mail: taeyoo88@, nsu.ac.kr)

C2015 The Society of Physical Therapy Science. Published by IPEC Inc. This is an open-access article distributed under the terms of the Creative Commons Attribution Non-Commercial No Derivatives (by-ncnd) License $<$ http://creativecommons.org/licenses/by-nc-nd/3.0/>. neus longus, and tibialis anterior muscles ${ }^{7}$. Small changes to adjustments in balance are accomplished by the action of the muscles associated with the ankle joints; the body movement around the ankle, acting like an inverted pendulum, corrects the position of the center of gravity ${ }^{2)}$.

Isometric, isotonic, and isokinetic exercises are used in resistance training for increasing muscle strength. Isotonic exercises are auxotonic contractions in which, despite changes in muscle length, tension in the muscles remains constant and improves muscle strength ${ }^{8)}$. Isokinetic exercises allow muscles to exert maximum strength within the range of all joint movements at a constant speed; various exercise methods can be used to improve muscle strength ${ }^{9}$. Isometric exercises are popular and have been performed successfully by physiotherapists for rehabilitation. In particular, they can be adjusted for patients whose range of joint movements is limited, and they are useful when performed in a safe training environment ${ }^{10)}$. Muscle fatigue, which is a hindrance factor during exercise, is defined as a condition that brings about a reduction in maximum voluntary force or power generated by a muscle or muscle group; the muscle fatigue mechanism is a complex phenomenon in which the central and peripheral nervous systems generally work together ${ }^{11)}$. In order to evaluate the mechanisms of muscular strength production, muscle activities were studied using a direct measurement technique. Muscle movement begins with an electrical activity, and this signal is recorded by electromyography $(\mathrm{EMG})^{8)}$. Determining the level of muscle activ- 
ity is a non-invasive method of studying the electrical and mechanical events of a single muscle excitation-contraction combination; recording the electrical activity of muscles has been widely used in studies on muscle coordination, muscle contraction characteristics, motor unit recruitment, and the muscle firing rate ${ }^{12)}$

In previous studies of patients with knee osteoarthritis that compared isometric and isokinetic exercises, it was found that isokinetic exercises were much more effective than isometric exercises for improving muscle strength ${ }^{13)}$. Yang and Hwang ${ }^{14)}$ reported that a six-week treatment of neurological physical therapy with afferent knee joint isokinetic exercises in patients with acute stroke and hemiplegia improved balance control and muscle strength in the lower extremities. In addition, an analysis of the muscle activities of volleyball players who received isometric training for six weeks found that there were significant differences in the improvement of muscle strength ${ }^{8)}$. After isokinetic exercises were performed for four weeks on the ankle joints of adults in their $20 \mathrm{~s}$, the subjects were asked to complete a one-leg stance on the same leg, and it was reported that the ankle muscle training helped to improve balance control ${ }^{6)}$.

The plantar flexor of the ankle joint is considered to be the key regulator in standing ${ }^{15}$ ), and it plays an important role ${ }^{16)}$ in walking efficiency ${ }^{17)}$. In the current study, isotonic, isokinetic, and isometric exercises were performed on ankle joints to assess their effects on the muscle activity and balance control of the tibialis anterior, peroneus longus, and gastrocnemius muscles.

\section{SUBJECTS AND METHODS}

The 30 participants in this study were students at a university in Cheonan, Republic of Korea. The procedures of the experiment were explained to the students, who did not have any problems with the experiment and voluntarily agreed to participate. Exclusion criteria included musculoskeletal or neurological diseases; muscle strength training during the past six months ${ }^{18)}$; joint or bone disorders or ankle sprains; and tendon, fascia, or ligament inflammation ${ }^{19)}$. The exercises were divided into isotonic, isokinetic, and isometric exercises, and 10 students were randomly assigned to each of the three types of exercise groups.

A body composition analyzer (InBody720, Biospace O. Ltd., Seoul, Republic of Korea) was used to determine the general characteristics of the subjects. A Functional Rehab System (PRIMUS RS, BTE Tech., Hanover, MD, USA) was employed to carry out the isotonic, isokinetic, and isometric exercises. A Free EMG system (Free EMG, BTS Inc., Milan, Italy) measure the muscle activity of the subjects, and a computerized balance platform (BT4, HUR Labs Oy., Tampere, Finland) was used to determine balance control.

After being informed about the study and understanding the purpose and content of the experiment, each of the 30 participants signed a consent form. After measuring their physical characteristics, ten students were randomly assigned to each of the three exercise groups: isotonic, isokinetic, and isometric. Before conducting the experiment, the dominant limb was identified by having the subjects kick a ball that had been placed in front of them. The limb that was used to kick the ball was identified as the dominant side ${ }^{20}$ in order to apply the exercise to the non-dominant side; surface electrodes were then attached to the tibialis anterior, peroneus longus, and gastrocnemius muscles.

The subjects were positioned in the physical rehabilitation equipment with their knees fully extended ${ }^{21)}$, and both sides of the hip joints and the knee joints were fixed into a neutral position using a strap. The exercises were performed after fitting the rotational axis of the equipment along the inner elongation of the anklebone with the foot secured in the isokinetic equipment ${ }^{22}$. The equipment was calibrated before every exercise was performed ${ }^{23)}$. The isometric exercises were performed three times to induce muscle fatigue in the subjects for maximal voluntary isometric contraction $(\mathrm{MVIC})^{24)}$. There was a one-minute rest period between each attempt $^{25)}$. Of the three MVICs, the one with the highest peak torque was selected as the MVIC ${ }^{15}$ ). Then the subjects were given verbal reinforcement to encourage them to exert maximum force during the isometric contractions ${ }^{24)}$. To familiarize the subjects with the experiment before performing the isotonic, isometric, or isokinetic exercises, submaximal contractions were performed five times as a pre-exercise that involved isokinetic exercises ${ }^{26}$. There was a five-minute rest period after the pre-exercise to prevent the fatigue effect ${ }^{27)}$. The isotonic exercise group performed self-paced exercises $^{28)}$ at $50 \%$ resistance of MVIC ${ }^{29)}$. Ten repetitions were performed per set, followed by a rest; three sets were performed, with a one-minute rest period between the sets to prevent fatigue ${ }^{30)}$. In the isokinetic exercise group, changes in the increase of muscle strength occurred according to isokinetic strength exercise implementation, which depends on the dynamic form of exercise, speed, and muscle contraction. In particular, low-velocity exercises generally increase muscle strength, while high-velocity exercises are mainly used for the recovery of muscle endurance. Among the most frequently implemented angular velocities of 60,180, and 300 degrees/sec in isokinetic exercises, the angular velocity of 60 degrees/sec was selected; this velocity is mainly used for improving muscle strength in adults or athletes ${ }^{31)}$. The ankle was put in a neutral position ${ }^{32)}$, and the exercise intensity was set within the range of pain tolerance. Three sets of ten repetitions of plantar flexion and dorsiflexion were performed, followed by a rest ${ }^{33}$. There was a one-minute rest period between sets to prevent the fatigue effect ${ }^{32)}$. The isometric strength training group used MVIC resistance to perform plantar flexion; dorsiflexion was performed at $70 \%$ of MVIC resistance ${ }^{21)}$. Plantar flexion and dorsiflexion of the ankle were sustained for 15 seconds $^{33)}$ per repetition for a total of three repetitions per set, and each set was followed by a five-second rest period ${ }^{30)}$; three total sets were performed. There was a one-minute rest period between each set to prevent fatigue ${ }^{32}$. In order to enable maximum performance, strong verbal reinforcement was provided during all tests, along with auditory and visual feedback ${ }^{15}$.

To generate the EMG data, electrodes were attached to the surface at the state of standard maximum contraction to avoid technical errors that might affect the tests. To minimize errors caused by skin impedance and to keep the impedance below $5 \mathrm{k} \Omega$, the skin was prepared first by exfoliation with sandpaper to remove dead skin cells and debris 
Table 1. Subject characteristics

\begin{tabular}{lccccc}
\hline \multirow{2}{*}{ Group } & \multirow{2}{*}{$\mathrm{N}$} & Age (years) & Height $(\mathrm{cm})$ & Weight $(\mathrm{kg})$ & $\mathrm{BMI}\left(\mathrm{kg} / \mathrm{m}^{2}\right)$ \\
\cline { 3 - 6 } & 10 & $\mathrm{M} \pm \mathrm{SD}$ & $\mathrm{M} \pm \mathrm{SD}$ & $\mathrm{M} \pm \mathrm{SD}$ & $\mathrm{M} \pm \mathrm{SD}$ \\
\hline Isotonic & $20.3 \pm 1.7$ & $170.2 \pm 9.9$ & $70.0 \pm 14.6$ & $23.9 \pm 2.6$ \\
Isokinetic & 10 & $20.2 \pm 1.8$ & $165.5 \pm 9.9$ & $65.8 \pm 20.2$ & $23.6 \pm 4.8$ \\
Isometric & 10 & $20.1 \pm 1.4$ & $166.9 \pm 11.5$ & $68.5 \pm 18.2$ & $24.1 \pm 3.9$ \\
\hline
\end{tabular}

$\mathrm{M} \pm \mathrm{SD}$ : means \pm standard deviation; BMI: body mass index

and then disinfection with sterile alcohol ${ }^{23)}$. All active electrodes (Carbon electrode; $3 \mathrm{M}$,) were attached parallel to the direction of the muscle fiber at $2-\mathrm{cm}$ intervals ${ }^{34)}$. A $1-\mathrm{kHz}$ sampling rate, $500-\mathrm{Hz}$ low-pass filter, and $20-\mathrm{Hz}$ high-pass filter were used to measure EMG. The EMG signals of each muscle measured were treated with the value of root mean square. Data for the EMG measurements were obtained by eliminating the beginning and end of the EMG interval.

To test the subjects' balance ability, a one-leg stance with eyes open was performed using a computerized balance platform. While standing barefoot with both arms comfortably at their sides ${ }^{35)}$, the subjects were asked to bend one leg along the anterior-posterior axis of the balance platform at $30^{\circ}$ and stand on the opposite leg, to maintain as stable a stance as possible ${ }^{36)}$ with their eyes open for 30 seconds $^{37)}$, and to gaze at a point on a monitor $65 \mathrm{~cm}$ away ${ }^{35)}$. An oral countdown from 4 seconds to 1 second was given to start, and the word "stop" was presented after the measurement was complete. These tests took place in a quiet environment ${ }^{38)}$. Data were obtained by taking the mean value of the measurements, which were repeated twice.

The data measured in this study were analyzed using SPSS ver. 18.0. General characteristics were expressed as mean and standard deviation. The Kolmogorov-Smirnov test was used to demonstrate a normal distribution, and the Levene F-test was used to verify the homogeneity of the subjects. Multivariate analysis of variance (MANOVA) was used to compare the difference in muscle activity and balance control in the tibialis anterior, medial gastrocnemius, and peroneus longus, depending on the group (isotonic, isokinetic, or isometric exercise group) and time (pre- or post-exercise). When there was a significant difference, the Scheffé test was used for post-hoc analysis. The statistical significance level was set at $\alpha=0.05$. This study was approved by the Institutional Review Board of Namseoul University (Cheonan, Korea, NSU-140528-1).

\section{RESULTS}

Thirty healthy adult subjects participated in this study. Fifteen of the subjects were male, and 15 were female; 28 of the subjects were right-side dominant, and two were left-side dominant. Information regarding the subjects, such as age, height, weight, and body mass index, is provided in Table 1 .

The changes in muscle activity before and after the tests are shown in Table 2. The statistical analysis indicated that no interaction between group and time could be observed in any of the subjects. The main effects of time were also not observed. The main effects according to group could be
Table 2. Comparison of pre- and post-test muscle electromyography $(\mathrm{mV})$

\begin{tabular}{lccc}
\hline \multirow{2}{*}{ Variable } & \multirow{2}{*}{ Group } & Pre-test & Post-test \\
\cline { 3 - 4 } Non-TA* & Isotonic $^{\mathrm{b}}$ & $0.35 \pm 0.30$ & $0.33 \pm 0.14$ \\
(support by & Isokinetic $^{\text {ac }}$ & $1.47 \pm 1.52$ & $1.18 \pm 0.83$ \\
non-) & Isometric $^{\mathrm{b}}$ & $0.52 \pm 0.53$ & $0.42 \pm 0.18$ \\
Non-GCM* & Isotonic $^{*}$ & $1.21 \pm 1.37$ & $1.86 \pm 2.17$ \\
(support by $_{\text {non-) }}$ & Isokinetic $^{\mathrm{c}}$ & $2.13 \pm 2.31$ & $2.81 \pm 2.40$ \\
Non-PL* & Isometric $^{\mathrm{b}}$ & $0.76 \pm 0.54$ & $0.73 \pm 2.17$ \\
(support by & Isotonic $^{*}$ & $0.83 \pm 1.01$ & $0.94 \pm 0.86$ \\
non-) & Isokinetic $^{\mathrm{c}}$ & $1.59 \pm 1.26$ & $1.78 \pm 1.76$ \\
dom-GCM* & Isometric $^{\mathrm{b}}$ & $0.76 \pm 0.54$ & $0.73 \pm 0.52$ \\
(support by & Isotonic $^{\mathrm{b}}$ & $0.57 \pm 0.59$ & $1.37 \pm 2.14$ \\
dom-) & Isokinetic $^{\text {ac }}$ & $2.35 \pm 1.62$ & $2.42 \pm 2.25$ \\
& Isometric $^{\mathrm{b}}$ & $0.61 \pm 0.37$ & $0.76 \pm 0.50$ \\
dom-PL & Isotonic $^{\mathrm{b}}$ & $0.62 \pm 0.58$ & $1.01 \pm 0.83$ \\
(support by & Isokinetic $^{\text {ac }}$ & $1.40 \pm 0.90$ & $1.87 \pm 1.23$ \\
dom-) & Isometric $^{\mathrm{b}}$ & $0.82 \pm 0.75$ & $1.04 \pm 0.69$ \\
\hline
\end{tabular}

${ }^{*} \mathrm{p}<0.05$; ${ }^{\mathrm{i}}$ isotonic; ${ }^{\mathrm{b}}$ isokinetic; ${ }^{\mathrm{c}}$ isometric; non-: non-dominant side; dom-: dominant side; TA: tibialis anterior; GCM: gastrocnemius; PL: peroneus longus

observed in the non-dominant tibialis anterior, gastrocnemius, and peroneus longus muscles when the non-dominant limb was weight bearing, and in the peroneus longus and gastrocnemius muscles when the dominant limb was weight bearing. A multiple comparison analysis showed that there were significant differences among the isokinetic, isotonic, and isometric exercise groups in the non-dominant tibialis anterior and between the isokinetic and isometric exercise groups in the non-dominant gastrocnemius and peroneus longus. In addition, there were significant differences among the isokinetic, isotonic, and isometric exercise groups in the dominant gastrocnemius and peroneus longus.

The changes in balance control according to group both before and after the tests are shown in Table 3. Statistical analysis revealed no interaction between group and time. No main effect according to group was observed, and the main effect of time on surface area was present only when the non-dominant and dominant sides were weight bearing. Multiple comparison analysis of the significant differences in surface area showed that when the non-dominant side was weight bearing, there were significant differences in all three exercise groups; when the dominant side was weight bear- 
1878 J. Phys. Ther. Sci. Vol. 27, No. 6, 2015

Table 3. Comparison of pre- and post-test balance

\begin{tabular}{lccc}
\hline \multirow{2}{*}{ Variable } & \multirow{2}{*}{ Group } & Pre-test & Post-test \\
\cline { 3 - 4 } & & $\mathrm{M} \pm \mathrm{SD}$ & $\mathrm{M} \pm \mathrm{SD}$ \\
\hline \multirow{2}{*}{ Area $\left(\mathrm{mm}^{2}\right.$ ) } & Isotonic & $435.0 \pm 139.1$ & $615.1 \pm 244.1^{+}$ \\
(support by non-) & Isokinetic & $389.3 \pm 215.6$ & $515.6 \pm 277.7^{+}$ \\
& Isometric & $292.6 \pm 138.1$ & $491.5 \pm 280.5^{+}$ \\
& Isotonic & $399.1 \pm 151.5$ & $495.0 \pm 229.2$ \\
Area $\left(\mathrm{mm}^{2}\right.$ ) & Isokinetic & $353.5 \pm 119.8$ & $453.4 \pm 161.6^{+}$ \\
(support by dom-) & Isometric & $349.2 \pm 149.4$ & $470.2 \pm 295.8$ \\
& Isotonic & $11.5 \pm 4.0$ & $12.2 \pm 3.0$ \\
Velocity (mm/s) & Isokinetic & $12.3 \pm 3.7$ & $13.4 \pm 3.6$ \\
(support by non-) & Isometric & $11.4 \pm 2.8$ & $16.3 \pm 13.8$ \\
& Isotonic & $11.7 \pm 3.2$ & $11.1 \pm 2.6$ \\
Velocity (mm/s) & Isokinetic & $12.3 \pm 2.8$ & $14.4 \pm 6.2$ \\
(support by dom-) & Isometric & $12.0 \pm 3.5$ & $14.7 \pm 8.5$ \\
\hline
\end{tabular}

${ }^{*} \mathrm{p}<0.05 ;{ }^{+}<0.05$ : compared with post-test; non-: non-dominant side; dom-: dominant side

ing, there were only significant differences in the isokinetic exercise group.

\section{DISCUSSION}

The ankle strategy requires a normal operating range and muscle strength, and it is used to maintain balance. If the range of movement of the ankle joints becomes constrained, the postural adjustment provided by the ankle joints becomes constrained as well ${ }^{5}$. Postural adjustments require integration of body segment movement navigation and the information sent through the central nervous system through the proprioception, tactile, visual, and afferent systems; muscle fatigue influences one or more regulatory systems, such as postural adjustment, and it is typically associated with changes in movement and sensory systems ${ }^{39)}$.

In this study, the subjects were young, healthy adults who performed isotonic, isokinetic, and isometric exercises of the ankle joints; this study analyzed the effects these exercise methods have on the muscle activity and balance control of the tibialis anterior, gastrocnemius, and peroneus longus muscles. In the case of muscular activity, there were significant differences in the non-dominant tibialis anterior, gastrocnemius, and peroneus muscles when the non-dominant side was weight bearing; when the dominant-side was weight bearing, there were significant differences in the dominant gastrocnemius and peroneus longus muscles. In the case of balance, there were significant differences in surface area, depending on time when both the non-dominant side and the dominant side were weight bearing; however, no significant difference in velocity was observed.

Significant differences were noted in the EMG of the non-dominant tibialis anterior when the non-dominant limb was weight bearing. These results are consistent with previous research on the bilateral effects of muscle fatigue of one leg and muscle EMG, where it was found that the tibialis anterior muscle of the limb on which the exercise was performed experienced a decline in EMG. It was reported that this decline was related to resistance to stretching of the fatigued muscles, as fatigued muscle activity is usually associated with increased passive tension ${ }^{39)}$. Onambele et al. ${ }^{38)}$ analyzed the muscular activity of the plantar flexor and dorsiflexor muscles in elderly and young adult patients by having them perform a one-leg stance with their eyes closed, and they found that the EMG of the tibialis anterior was higher than that of the gastrocnemius in both groups. When a one-leg stance with eyes open was performed, EMG was higher in the tibialis anterior of the elderly group and higher in the gastrocnemius of the young adult group. The findings were similar in the current study, in which adults in their 20s were the subjects; in addition, the EMG of the non-dominant gastrocnemius was higher than the non-dominant EMG of the tibialis anterior when the non-dominant limb was weight bearing. These results indicate that due to the muscle fatigue induced by the three exercises, the EMG activity of the tibialis anterior declined in relation to the resistance to muscle activity by the muscle that had been fatigued by the one-leg stance with eyes open.

In a study regarding the effects of fatigue during isometric contractions of both the dominant and non-dominant quadriceps muscles, it was found that initial recovery from the combined effect of the fatigue mechanisms that contribute to the maximum decline in power due to sustained isometric contraction was in the dominant leg. This result occurred even though the combined effect of the peripheral and central fatigue mechanisms that induce the development of muscle fatigue during continuous isometric contraction of one side was not related to the dominant leg ${ }^{40)}$. In addition, in a study on postural adjustment disturbance of the opposite leg in a one-leg stance brought on by fatigue induced by stimulation and voluntary contraction of the same limb (the exercised lower extremities), it was reported that the cross-over fatigue effect after stimulation and voluntary contraction could interfere with postural adjustment. The training of one weight-bearing side could also be transferred to the untrained side due to the cross-education effect ${ }^{41)}$. Thus, in this study, the unexercised, dominant side showed significant differences in the gastrocnemius and peroneus longus when the dominant leg was weight-bearing due to this effect, while the unexercised dominant gastrocnemius and peroneus longus developed tiredness before muscle fatigue. Moreover, the lack of significant differences in the dominant tibialis anterior muscle when the dominant side was weight-bearing might be due to the morphological characteristics of the muscles: the plantar flexor, which is composed of cooperative muscles, has a high compensation potential, but the muscle fatigue recovery rate is slow, while the dorsiflexor has relatively low compensation potential but a fast fatigue recovery rate.

In this study, the results of balance ability both before and after exercise in the respective exercise groups showed that there were significant differences in the dominant and nondominant weight-bearing sides in terms of area. In a previous study, in which young adults performed a 30 -second one-leg stance on their dominant leg after inducing isokinetic fatigue in the ankle and hip joints, there was no significant difference in the area of the ankle joint, even though the area tended to increase after the fatigue rather than before the fatigue ${ }^{42)}$. In 
a study on changes in balance orientation of healthy elderly women after knee and ankle fatigue, it was found that acute muscle fatigue reduced balance adjustment ${ }^{43}$ ) and localized dorsiflexor fatigue from the midsagittal plane was a leading factor in precipitating postural adjustment disturbance; this was found to produce a higher average disturbance threshold during posture correction than the plantar flexor in a nonfatigued state ${ }^{44)}$. The analysis of the effects of ankle muscle fatigue on one-leg stance posture control and recovery in adult male and female subjects showed that there were no gender differences; the fatigue effect appeared in the right and left factors both before and after fatigue in both the male and female groups ${ }^{45}$. In a study in which young adults performed a one-leg stance with their eyes open after isokinetic fatigue had been induced in the ankle, knee, and hip joints, it was found that from the coronal plane, knee and hip joint fatigue brought about disturbances to posture adjustment; however, midsagittally, the fatigue of the three joints produced posture adjustment disturbances ${ }^{46}$ ). Similarly, as in previous studies, the lower extremity fatigue induced by the three exercise methods implemented in this study affected the posture adjusting mechanisms. The sway area also increased significantly before and after the exercises. Even the non-dominant side, which did not perform the exercises, was affected before the fatigue; thus, the transferred fatigue caused postural sway to increase significantly. This outcome shows the direct effect of plantar flexor and dorsiflexor fatigue of the ankle joints.

In this study, there were no significant differences in velocity before or after the exercises depending upon the group. According to a study on the effects of ankle and hip joint muscle fatigue on postural sway in a one-leg stance, muscle fatigue of the plantar flexor and dorsiflexor of the ankle joints did not increase the sway velocity compared with the muscle fatigue in the flexion and extensor muscles of the hip joints; muscles that are proximal (hip and knee) exert a greater influence on posture adjustment than muscles that are distal (ankle). The use of the hip joint strategy increases according to the difficulty of the tasks - however, the ankle strategy is primarily used when standing. Thus, the one-leg stance is adjusted by a combination of hip and ankle joints. When the ankle joints are fatigued, decreased ankle joint control (due to a damaged ankle proprioceptive sense) can be compensated for by increased dependency on the hip strategy ${ }^{42}$. A study analyzing the effects of vision on postural control and muscle fatigue in triceps surae muscles ${ }^{47)}$ reported that vision can bring about postural deficiency related to fatigue in the plantar flexor. In addition, in a study of postural sway during one-leg stance, lower body angle and postural strategy, and the effects of plantar flexor and dorsiflexor fatigue, it was found that visual senses compensated for compromised postural adjustment. A proprioceptive sensory deficit strengthened the role of vision and subsequently reduced the amount of proprioceptive sensory information necessary to stand on one leg, particularly when the support surface decreased ${ }^{37)}$. In a study of healthy athletes and athletes with functional ankle instability that investigated the effects of fatigue due to treadmill running and sensorimotor control, it was found that fatigue due to treadmill running had negative effects on static and dynamic posture control assessment in all groups.
That finding indicates that damage has occurred to muscle activation patterns and reflex activity; in the state of fatigue, postural adjustment is affected by complex mechanisms of the sensory, neural-muscular, and central nervous systems; the central nervous system receives more disturbances than the peripheral mechanisms of proprioception ${ }^{48)}$.

Moreover, in a study on posture sway and the effects of incremental difficulties in a standing balance task with visual feedback, as the difficulty of the task increased, the amplitude of the postural sway increased, and the fuzzy entropy of postural sway also increased from the anteroposterior axis in the most unstable condition ${ }^{49)}$. According to a study on visual compensation in accordance with muscle fatigue and postural adjustment, different sensory systems exist in a complex relationship related to postural control. Under the condition of muscle fatigue, vision can compensate for the muscle fatigue generated by the triceps surae muscle by increasing the contributions of the various sensory systems for adjusting posture. Concurrently, in the state of muscle fatigue, the effectiveness of the visual presentation is important for proper adjustment of support ${ }^{47)}$. Therefore, the reason there was no significant difference in velocity/speed was because the balance was measured in a one-leg stance with eyes open without constraining the subject's vision. Due to the muscle fatigue, compensation from visual information regarding postural adjustment and dependence on the hip strategy were amplified; the impairment of the sensorimotor system and proprioception of the ankle joints for maintaining balance were not sufficient to make a significant impact on velocity.

This study analyzed the effects of muscle fatigue on muscle activity and balance control in the lower extremities using three exercise methods. The ankle joint in which this was implemented was limited; balance was measured with visual information, and the subjects were confined to healthy students. For further research, studies regarding the relationship and compensation potential of various joints, such as hip, knee, and ankle joints; studies on postural and balance control both with and without visual information, as vision and proprioception are closely related ${ }^{50)}$; and research focusing on specialized groups, such as patients and athletes with pain or disease in the ankle joint, are needed to expand the scope and variety of the research.

In conclusion, in this study, isotonic, isokinetic, and isometric exercises were applied to the ankle joints of healthy adults in their 20 s to investigate the effects of these exercise methods on the muscle activity and balance control of the tibialis anterior, inner gastrocnemius, and peroneus longus muscles. Our results indicated that 1) there were no significant differences due to the changes of muscle activity before, during, or after the exercise between the interaction of group and time; however, there were significant differences according to group in the non-dominant tibialis anterior, gastrocnemius, and peroneus longus muscles when the non-dominant side was weight-bearing, as well as in the dominant gastrocnemius and peroneus longus when the dominant side was supported; 2) there were no significant differences before or after exercise in the interaction of group and time due to the change in balance control; depending on time, there were significant differences in the surface 
1880 J. Phys. Ther. Sci. Vol. 27, No. 6, 2015

area depending upon whether the non-dominant side or the dominant side was weight-bearing, but there was a significant difference in speed. Accordingly, the muscle fatigue generated by the three exercise methods affected the decline in muscle activity and balance control; it also influenced the side that did not perform the exercise before fatigue due to this effect. The finding that visual compensation occurs to maintain postural balance will further aid future treatment and research regarding muscle activity and balance control in the lower extremities.

\section{REFERENCES}

1) Lee SY, Hong MH, Park MC, et al.: Effect of the mandibular orthopedic repositioning appliance on trunk and upper limb muscle activation during maximum isometric contraction. J Phys Ther Sci, 2013, 25: 1387-1389. [Medline] [CrossRef]

2) Ozyemisci-Taskiran O, Özdoğan V, Sepici V, et al.: Test-retest and interrater reliability of isokinetic ankle dorsiflexor and plantar flexor strength measurement in healthy adults. Turk J Phys Med Rehab, 2013, 59: 32-35.

3) Soda N, Ueki T: Electromyography study of forward-stepping motion. J Phys Ther Sci, 2013, 25: 615-617. [Medline] [CrossRef]

4) Gao F, Ren Y, Roth EJ, et al.: Effects of repeated ankle stretching on calf muscle-tendon and ankle biomechanical properties in stroke survivors. Clin Biomech (Bristol, Avon), 2011, 26: 516-522. [Medline] [CrossRef]

5) Park YH, Kim YM, Lee BH: An ankle proprioceptive control program improves balance, gait ability of chronic stroke patients. J Phys Ther Sci, 2013, 25: 1321-1324. [Medline] [CrossRef]

6) Son SM, Kang KW, Lee NK, et al.: Influence of isokinetic strength training of unilateral ankle on ipsilateral one-legged standing balance of adults. J Phys Ther Sci, 2013, 25: 1313-1315. [Medline] [CrossRef]

7) Yuk GC: The acute effects of 15 minutes plantarflexor static stretch in quite stance. J Korean Soc Phys Med, 2012, 7: 191-197. [CrossRef]

8) Rezaeimanesh D, Farsani PA: The effect of a 6 week isotonic training period on lower body muscle emg changes in volleyball players. Procedia Soc Behav Sci, 2011, 30: 2129-2133. [CrossRef]

9) Lee SB, Kang KY: The effects of isokinetic eccentric resistance exercise for the hip joint on functional gait of stroke patients. J Phys Ther Sci, 2013, 25: 1177-1179. [Medline] [CrossRef]

10) Moon J, Shin I, Kang M, et al.: The effect of shoulder flexion angles on the recruitment of upper-extremity muscles during isometric contraction. J Phys Ther Sci, 2013, 25: 1299-1301. [Medline] [CrossRef]

11) Ishii $H$, Nishida $Y$ : Effect of lactate accumulation during exercise-induced muscle fatigue on the sensorimotor cortex. J Phys Ther Sci, 2013, 25: $1637-$ 1642. [Medline] [CrossRef]

12) Madeleine P, Bajaj P, Søgaard K, et al.: Mechanomyography and electromyography force relationships during concentric, isometric and eccentric contractions. J Electromyogr Kinesiol, 2001, 11: 113-121. [Medline] [CrossRef]

13) Rosa UH, Velásquez Tlapanco J, Lara Maya $\mathrm{C}$, et al.: [Comparison of the effectiveness of isokinetic vs isometric therapeutic exercise in patients with osteoarthritis of knee]. Reumatol Clin, 2012, 8: 10-14. [Medline] [CrossRef]

14) Yang JS, Hwang BK: Effects of concentric isokinetic knee strength training on balance and strength of knee muscle in acute hemiparetic stroke patients. J Coach Develop, 2009, 11: 181-189.

15) Bisson EJ, Remaud A, Boyas S, et al.: Effects of fatiguing isometric and isokinetic ankle exercises on postural control while standing on firm and compliant surfaces. J Neuroeng Rehabil, 2012, 9: 39. [Medline] [CrossRef]

16) Gajdosik RL, Vander Linden DW, McNair PJ, et al.: Effects of an eightweek stretching program on the passive-elastic properties and function of the calf muscles of older women. Clin Biomech (Bristol, Avon), 2005, 20 973-983. [Medline] [CrossRef]

17) Salsich GB, Mueller MJ: Effect of plantar flexor muscle stiffness on selected gait characteristics. Gait Posture, 2000, 11: 207-216. [Medline] [CrossRef]

18) Yoon DS, Kim TH, Shin HS, et al.: The Effects of the angle of ankle joints and direction of isometric contraction on fatigue in the contralateral muscle. Kor Res Soc Phys Ther, 2005, 12: 46-55.

19) Borreani S, Calatayud J, Martin J, et al.: Exercise intensity progression for exercises performed on unstable and stable platforms based on ankle muscle activation. Gait Posture, 2014, 39: 404-409. [Medline] [CrossRef]
20) Cramer JT, Beck TW, Housh TJ, et al.: Acute effects of static stretching on characteristics of the isokinetic angle-torque relationship, surface electromyography, and mechanomyography. J Sports Sci, 2007, 25: 687-698. [Medline] [CrossRef]

21) Kennedy A, Hug F, Bilodeau M, et al.: Neuromuscular fatigue induced by alternating isometric contractions of the ankle plantar and dorsiflexors. J Electromyogr Kinesiol, 2011, 21: 471-477. [Medline] [CrossRef]

22) Jun AY, Hwang BG, Cho SH, et al.: Recovery of muscle power following early weight-bearing and ankle exercise after surgical repair of acute achilles tendon rupture. J Kor Orthop Assoc, 2012, 47: 111-118. [CrossRef]

23) Byun YH, Lee HH, Han SH: Surface EMG analysis of quadriceps muscle during isokinetic exercise in patients with patellofemoral pain. J coach develop, 2007, 9: 157-164.

24) Hertel J, Earl JE, Tsang KK, et al.: Combining isometric knee extension exercises with hip adduction or abduction does not increase quadriceps EMG activity. Br J Sports Med, 2004, 38: 210-213. [Medline] [CrossRef]

25) Sesto ME, Chourasia AO, Block WF, et al.: Mechanical and magnetic resonance imaging changes following eccentric or concentric exertions. Clin Biomech (Bristol, Avon), 2008, 23: 961-968. [Medline] [CrossRef]

26) DeStaso J, Kaminski TW, Perrin DH: Relationship between drop vertical jump heights and isokinetic measures utilizing the stretch-shortening cycle. Isokinet Exerc Sci, 1997, 6: 175-179.

27) Brughelli M, Mendiguchia J, Nosaka K, et al.: Effects of eccentric exercise on optimum length of the knee flexors and extensors during the preseason in professional soccer players. Phys Ther Sport, 2010, 11: 50-55. [Medline] [CrossRef]

28) Fang Y, Siemionow V, Sahgal V, et al.: Distinct brain activation patterns for human maximal voluntary eccentric and concentric muscle actions. Brain Res, 2004, 1023: 200-212. [Medline] [CrossRef]

29) Webber SC, Porter MM: Reliability of ankle isometric, isotonic, and isokinetic strength and power testing in older women. Phys Ther, 2010, 90: 1165-1175. [Medline] [CrossRef]

30) Sanavi HM, Zafari A, Firouzi M: The effect of 10 -sec of maximal voluntary isometric contraction and 10 -sec of passive stretching on strength, endurance and flexibility of hamstring muscle. Ann Bio Res, 2012, 3: 1480-1484.

31) Bang HS, Kim JS: The effects of angular velocity on muscle strength of biceps brachii. J Kor Soc Phys Med, 2009, 4: 157-164.

32) Hwang IS, Abraham LD: Quantitative EMG analysis to investigate synergistic coactivation of ankle and knee muscles during isokinetic ankle movement. Part 1: time amplitude analysis. J Electromyogr Kinesiol, 2001, 11: 319-325. [Medline] [CrossRef]

33) Oshita K, Yano S: Asymmetry of force fluctuation during low intensity isometric contraction in leg muscle. Inter J Exer Sci, 2010, 3: 68-77.

34) Murley GS, Bird AR: The effect of three levels of foot orthotic wedging on the surface electromyographic activity of selected lower limb muscles during gait. Clin Biomech (Bristol, Avon), 2006, 21: 1074-1080. [Medline] [CrossRef]

35) Lee AJ, Lin WH: Twelve-week biomechanical ankle platform system training on postural stability and ankle proprioception in subjects with unilateral functional ankle instability. Clin Biomech (Bristol, Avon), 2008, 23: 1065-1072. [Medline] [CrossRef]

36) Muehlbauer $T$, Roth R, Mueller $S$, et al.: Intra and intersession reliability of balance measures during one-leg standing in young adults. J Strength Cond Res, 2011, 25: 2228-2234. [Medline] [CrossRef]

37) Boyas S, Hajj M, Bilodeau M: Influence of ankle plantarflexor fatigue on postural sway, lower limb articular angles, and postural strategies during unipedal quiet standing. Gait Posture, 2013, 37: 547-551. [Medline] [CrossRef]

38) Onambélé GL, Narici MV, Rejc E, et al.: Contribution of calf muscle-tendon properties to single-leg stance ability in the absence of visual feedback in relation to ageing. Gait Posture, 2007, 26: 343-348. [Medline] [CrossRef]

39) Berger LL, Regueme SC, Forestier N: Unilateral lower limb muscle fatigue induces bilateral effects on undisturbed stance and muscle EMG activities. J Electromyogr Kinesiol, 2010, 20: 947-952. [Medline] [CrossRef]

40) Willems ME, Ponte JP: Divergent muscle fatigue during unilateral isometric contractions of dominant and non-dominant quadriceps. J Sci Med Sport, 2013, 16: 240-244. [Medline] [CrossRef]

41) Paillard T, Chaubet V, Maitre J, et al.: Disturbance of contralateral unipedal postural control after stimulated and voluntary contractions of the ipsilateral limb. Neurosci Res, 2010, 68: 301-306. [Medline] [CrossRef]

42) Bisson EJ, McEwen D, Lajoie Y, et al.: Effects of ankle and hip muscle fatigue on postural sway and attentional demands during unipedal stance. Gait Posture, 2011, 33: 83-87. [Medline] [CrossRef]

43) Bellew JW, Fenter PC: Control of balance differs after knee or ankle 
fatigue in older women. Arch Phys Med Rehabil, 2006, 87: 1486-1489. [Medline] [CrossRef]

44) Hlavackova P, Vuillerme N: Do somatosensory conditions from the foo and ankle affect postural responses to plantar-flexor muscles fatigue during bipedal quiet stance? Gait Posture, 2012, 36: 16-19. [Medline] [CrossRef]

45) Youm CH, Kim YH: Effects of induced fatigue of ankle joint muscle on the capability and recovery of postural control during single-leg stance. Kor J Sport Biomech, 2012, 22: 219-228. [CrossRef]

46) Gribble PA, Hertel J: Effect of lower-extremity muscle fatigue on postura control. Arch Phys Med Rehabil, 2004, 85: 589-592. [Medline] [CrossRef]

47) Vuillerme $\mathrm{N}$, Nougier V, Prieur JM: Can vision compensate for a lower limbs muscular fatigue for controlling posture in humans? Neurosci Lett,
2001, 308: 103-106. [Medline] [CrossRef]

48) Steib S, Hentschke C, Welsch G, et al.: Effects of fatiguing treadmill running on sensorimotor control in athletes with and without functional ankle instability. Clin Biomech (Bristol, Avon), 2013, 28: 790-795. [Medline] [CrossRef]

49) Barbado Murillo D, Sabido Solana R, Vera-Garcia FJ, et al.: Effect of increasing difficulty in standing balance tasks with visual feedback on postural sway and EMG: complexity and performance. Hum Mov Sci, 2012, 31: 1224-1237. [Medline] [CrossRef]

50) Park JH, Lee KS, Oh TY: The effects of visual field conditions on electromyography of the lower extremities during reaching tasks in healthy adults. J Phys Ther Sci, 2014, 26: 543-547. [Medline] [CrossRef] 